\title{
МЕТОД ФОРМИРОВАНИЯ СТРАТЕГИИ УПРАВЛЕНИЯ ИННОВАЦИОННЫМИ ПРОЕКТАМИ В ИНТЕЛЛЕКТОЕМКОЙ СФЕРЕ
}

\author{
(c) 2021 Шатохина Дарья Дмитриевна \\ факультет технологического менеджмента и инноваций, преподаватель \\ Национальный исследовательский университет ИТМО, Россия, Санкт-Петербург \\ E-mail: ddshatokhina@itmo.ru \\ (c) 2021 Будрин Александр Германович \\ факультет технологического менеджмента и инноваций, профессор, \\ профессор, доктор экономических наук \\ Национальный исследовательский университет ИТМО, Россия, Санкт-Петербург \\ E-mail:ag_budrin@mail.ru
}

Формирование интеллектоемкой сферы происходит за счет развития прорывных, инновационных отраслей экономики и требует развития управленческих инструментов. Предлагаемый метод формирования стратегии управления инновационными проектами в интеллектоемкой сфере учитывает выявленные в исследовании особенности интеллектоемкой сферы и потребности сотрудников как ключевой составляющей человеческого и интеллектуального капиталов.

Ключевые слова: стратегия управления, инновационные проекты, интеллектоемкая сфера, интеллектоемкие компании, человеческий капитал, интеллектуальный капитал, управление инновационными проектами, формирование стратегии управления.

Инновационная активность компаний в условиях экономики знаний является основой конкурентоспособности экономики страны и отдельных отраслей. На фоне формирования новых, передовых рынков, основанных на прорывных технологиях, происходит усиление роли человеческого капитала, который является ключевой базой формирования и роста капитала интеллектуального, что для большинства технологичных компаний означает повышенную конкуренцию за кадры, которые можно отнести к категории талантов - высококвалифицированные специалисты, в задачи которых входит разработка новых продуктов, услуг или процессов, насыщенная интеллектуальная деятельность [5]. Интеллектуальный капитал, а именно его качество, то, как бизнес-процессы компании способствуют его использованию и развитию, становится все более важен для выживания организаций на рынке. При этом существующие инструменты управления для данных компаний требуют улучшения, так как не учитывают все потребности упомянутых выше специалистов и особенности действия организаций в подобных условиях.

Упомянутые факторы позволяют говорить о выделении интеллектоемкой сферы, понимаемой авторами как системы экономических отношений, в которой успешность и конкурентоспо- собность отдельных бизнес-единиц зависит от уровня вклада интеллектуального капитала в их развитие. Формирование интеллектоемкой сферы происходит в настоящий момент путем взаимопроникновения и взаимостимулирования передовых, инновационных отраслей, в которых разработка и внедрение инноваций являются основой конкурентоспособности компаний, как и интеллектуальный капитал. Основной ресурс компаний, которые объединяет интеллектоемкая сфера, это высококвалифицированные сотрудники, занятые интеллектуальным и/или творческим трудом и созданием нового, так как именно от их работы зависит формирование и развитие непосредственно интеллектуального капитала. На основе анализа работ российских и зарубежных авторов, а также проведенного авторами исследования, которое включало кабинетные и полевые методы исследования, в том числе традиционный анализ документов, экспертные интервью (квотированная выборка, 9 респондентов), глубинные интервью (квотированная выборка, 12 респондентов), и проводилось на территории Российской Федерации и стран Евросоюза, можно выделить следующие особенности интеллектоемкой сферы:

- высокая роль знаний как нового товара, их производство - отдельный вид деятельности;

- высокая роль вклада интеллектуального и 
в его составе человеческого капитала в развитие компаний;

- высокая роль инноваций и инновационных продуктов в развитии и конкурентоспособности компаний, отсюда высокая потребность в инновациях;

- высокая скорость изменений во внешней среде и развития ключевых компаний-лидеров, как следствие, ограниченность временного ресурса постоянно у всех игроков;

- высокая неопределенность;

- высокая роль вклада творческого, нешаблонного и/или интеллектуального труда сотрудников в развитие компаний;

- зависимость конкурентоспособности компаний внутри сферы от качества и объема их интеллектуального капитала и его вклада в развитие компании.

Из описанных выше особенностей интеллектоемкой сферы вытекает специфика интеллектоемких компаний, под которыми понимаются компании, обладающие средним или высоким уровнем наличия нематериальных и интеллектуальных ресурсов, их накопления, использования в полной мере возможностей данных ресурсов и генерации прироста нематериальных и интеллектуальных ресурсов в целях развития компании и роста ее рыночной стоимости, а также формирующие соответствующую для данных процессов внутреннюю корпоративную среду. В качестве данной специфики подобных организаций можно выделить следующее:

- зависимость успешности развития компании от уровня качества и объема интеллектуального и, в его составе, человеческого капитала [6];

- зависимость развития и конкурентоспособности компаний от создания и внедрения инноваций и инновационных продуктов [3];

- высокая потребность компаний в инновациях [4];

- присутствие в бизнес-процессах компании инноваций нескольких типов одновременно (в качестве результата или в качестве процессной инновации);

- необходимость принятия решений и стратегических действий в условиях высокой неопределенности [7];

- значительная доля сотрудников, занимающихся интеллектуальным и/или творческим, нешаблонным трудом [9];

- необходимость работы в условиях ограниченности временного ресурса;

- необходимость работы в условиях посто- янной конкуренции за высокопрофессиональных сотрудников [1].

Таким образом, описанные выше компании оказываются под давлением сразу нескольких факторов, среди которых конкуренция в привлечении высококвалифицированных сотрудников, сложность в одновременном применении гибких методологий управления проектами и учете потребностей сотрудников в комфорте и времени на отдых, трудности в обеспечении прозрачности бизнес-процессов и документации, формировании открытой, поощряющей инициативу, открытой к новому и доброжелательной корпоративной культуры. Сочетание данных факторов с особенностями интеллектоемкой сферы и компаний приводят к необходимости формирования методологических инструментов, которые помогали бы осуществлять стратегическое управление организацией в подобных условиях.

Особенности интеллектоемкой сферы также, безусловно, влияют на специфику управления инновационными проектами компаний, действующих в данной сфере. В результате проведенного авторами исследования были выявлены и проанализированы ключевые пункты, отличающие управление инновационными проектами в интеллектоемкой сфере, которые важно учитывать при разработке стратегических решений организаций для стимулирования их инновационной активности. Во-первых, работе с инновационными проектами в интеллектоемкой сфере свойственна высокая степень неопределенности: в процессе менеджмента руководящие сотрудники принимают решения, зачастую не имея достаточной и полноформатной информации для этого, достаточных временных, человеческих, финансовых ресурсов. Данная особенность может влиять на компании и сотрудников, являющихся основными носителями человеческого капитала, как в положительную, стимулирующую сторону, так и в отрицательную, что может негативно сказываться на основных финансовых показателях компании. Во-вторых, одной из особенностей управления инновационными проектами в интеллектоемкой сфере можно назвать ограниченное количество временных ресурсов проекта на постоянной основе. Данная особенность вызывает высокий стресс сотрудников, которые вынуждены осуществлять интеллектуальную деятельность в режиме сжатых дедлайнов, эмоциональную усталость и потребность в усиленной немате- 
риальной и материальной мотивации сотрудников, а также создании качественных условий для их отдыха. В-третьих, учитывая важность персонала для осуществления инноваций и развития и усиления интеллектуального капитала компании, следующей важной особенностью менеджмента инновационных проектов в указанной сфере становится использование проектного подхода через призму управления человеческим капиталом компании. Решения по управлению проектами в интеллектоемких компаниях, осознающих свою специфику и зависимость конкурентоспособности организации от качества интеллектуального капитала должны приниматься исходя из важности каждого из сотрудников для компании, важности его профессионального и личностного развития, его психоэмоционального и физического состояния. В-четвертых, продолжая предыдущий пункт, в качестве специфики упомянутых проектов можно назвать внимание организации к развитию интеллектуально-творческих способностей сотрудников, которое в свою очередь, влияет на создание и внедрение инноваций в компании. Как показывают исследования [3], подобная мотивация сотрудников, занятых интеллектуальным трудом, и забота об их росте помогает повышать эффективность инновационных про- ектов. В-пятых, в качестве завершающей особенности можно упомянуть роль формирования и развития стимулирующей интеллектуальную инициативу сотрудников корпоративной культуры в инновационной деятельности организации. Корпоративная культура как составляющая отношенческого капитала в составе интеллектуального является одним из важнейших факторов, который или стимулирует и повышает инновационную и интеллектуальную активность сотрудников, либо наоборот, негативно влияет на инновационную деятельность.

Для закрытия потребности интеллектоемких компаний в методологическом инструменте, который позволял бы учитывать как особенности интеллектоемкой сферы, самой организации, так и сотрудников как ключевой составляющей человеческого и интеллектуального капитала был предложен метод формирования стратегии управления инновационными проектами в интеллектоемкой сфере. Данный метод состоит из 2 ступеней, каждая из которых включает в себя этапы, необходимые для разработки стратегических решений по управлению инновационными проектами в интеллектоемкой сфере, от аналитических до стратегических и нацеленных на внедрение данных решений. Общий вид метода представлен на рис. 1.

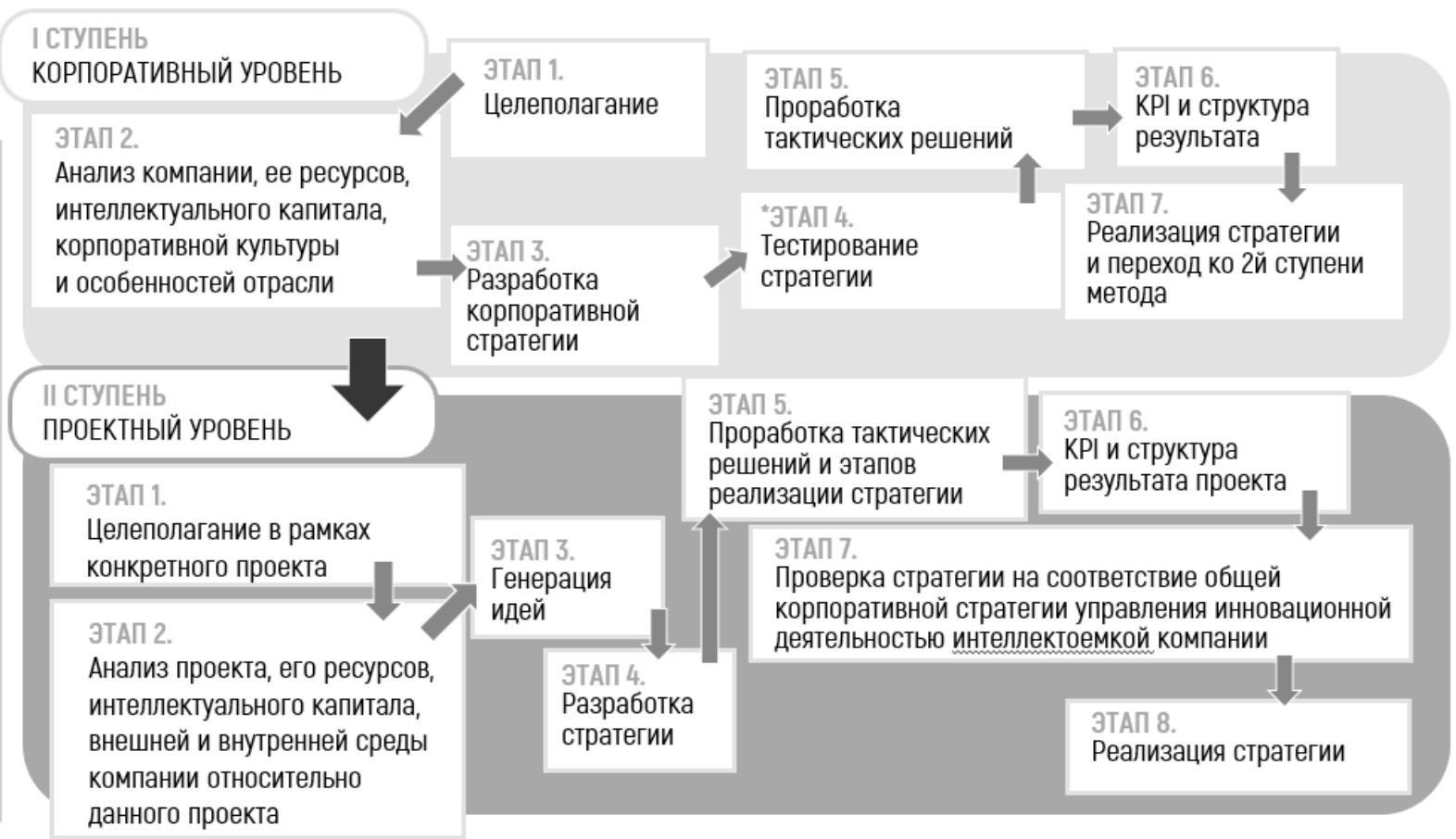

Рисунок 1. Концептуальный вид метода формирования стратегии управления инновационными проектами в интеллектоемкой сфере 
В результате применения ступени 1 описываемого метода компания получает корпоративную стратегию управления инновационной деятельностью интеллектоемкой компании на основе проектного подхода, которая является документом стратегического уровня и определяет этапность и специфику инновационной деятельности в компании, а также основные ценностные и концептуальные характеристики последующих документов, разрабатываемых на ступени 2 указанного метода: корпоративной политики управления среднесрочными проектами в компании (для создания общей инновационно-стимулирующей среды) и стратегии управления отдельным инновационным проектом стратегического уровня, которые разрабатываются по необходимости для каждого крупного инновационного проекта в компании. Подробнее описанная последовательность схематично представлена на рис. 2.
Таким образом, представленный метод формирования стратегии управления инновационными проектами в интеллектоемкой сфере позволяет разрабатывать стратегические решения относительно инновационной деятельности, учитывая специфику интеллектоемких компаний и их сотрудников, являющихся ключевым фактором обеспечения инновационной активности организаций, а также качественного роста их интеллектуального капитала.

Важным последствием применения описываемого метода формирования стратегии управления инновационными проектами в интеллектоемкой сфере является усиление интеллектоемкости организации. Для того, чтобы фиксировать изменения интеллектоемкости компании, необходимо рассмотреть возможности определения потенциала интеллектоемкости организации через призму человеческого капитала. На основе проведенных экспертных

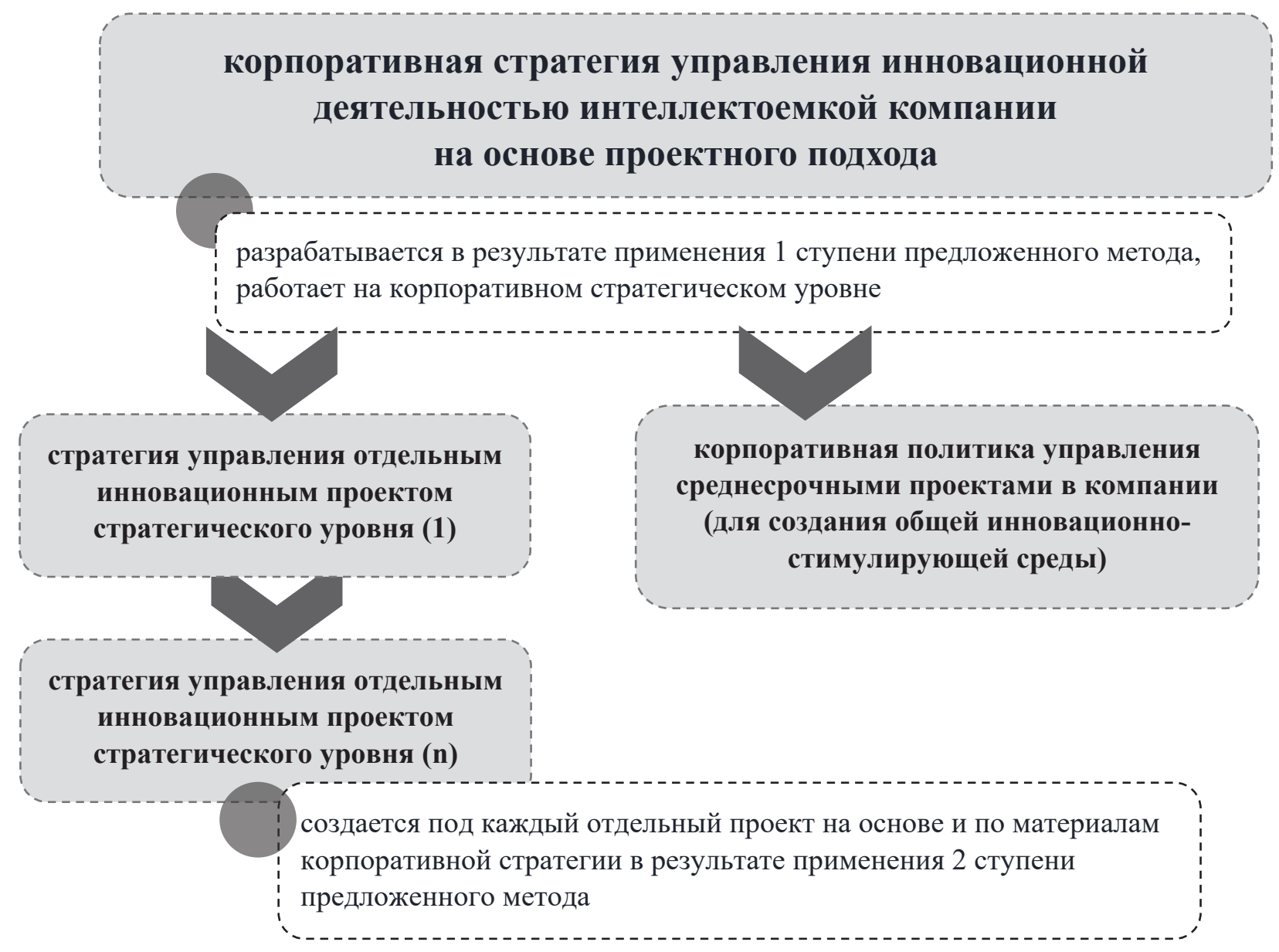

Рисунок 2. Последовательность применения метода формирования стратегии управления инновационными проектами в интеллектоемкой сфере в компании 
интервью и наблюдения за деятельностью компаний интеллектоемкой сферы потенциал интеллектоемкости компании был представлен в виде следующей формулы:

$$
\begin{aligned}
& \text { иеР } \mathrm{P}_{\text {орг }}=\text { количество сотрудников } \times \\
& \times \text { иеР } \mathrm{P} . \text { сотрудника }
\end{aligned}
$$

где иеР $\mathrm{opг}_{-}$- потенциал интеллектоемкости организации,

количество сотрудников - общее число сотрудников компании, занятых интеллектуальным и/или творческим трудом и созданием нового,

иеР $\mathrm{P}_{\text {ср.струдника }}$ - потенциал вклада среднего сотрудника, занятого интеллектуальным и/или творческим трудом и созданием нового.

Далее, потенциал вклада среднего сотрудника, занятого интеллектуальным и/или творческим трудом и созданием нового, был представлен следующей формулой:

$$
\text { иеР } \mathrm{P}_{\text {ср.сотрудника }}=\mathrm{x} \text { * } \mathrm{n} \text { * } \mathrm{m}
$$

где $\mathrm{x}$ - среднее число проектов на одного сотрудника,

$\mathrm{n}$ - индекс влияния внешних факторов,

$\mathrm{m}-$ индекс влияния внутренних факторов.

При этом переменная х может быть рассчи- тана следующим образом:

$$
\mathrm{x}=\frac{\mathrm{x}_{1} * \mathrm{x}_{2} * \mathrm{x}_{3} \ldots * \mathrm{x}_{\mathrm{y}}}{\mathrm{y}}
$$

где $\mathrm{x}_{1}$ - количество проектов, в которых задействован один сотрудник, занятый интеллектуальным и/или творческим трудом и созданием нового, при этом проекты различного уровня приводятся к единому знаменателю с помощью таблицы 1.

у - количество сотрудников, занятых интеллектуальным и/или творческим трудом и созданием нового.

Расчет индекса влияния внешних факторов (n) производится путем PEST-анализа с экспертной оценкой влияния каждого из факторов и дальнейшим их суммированием. Расчет индекса влияния внутренних факторов (m) происходит путем измерения приведенных показателей и экспертной оценки влияния факторов, представленных в таблице 2, а затем их суммированием.

Описанная последовательность оценки потенциала интеллектоемкости организации также представлена в качестве методики на рис. 3.

Таким образом, представленный авторами метод формирования стратегии управления инновационными проектами в интеллектоемкой сфере отвечает вызовам новых рынков, форми-

\section{Таблица 1. Коэффициенты для уравнения проектов по периоду реализации}

\begin{tabular}{|l|l|l|}
\hline краткосрочные & среднесрочные & долгосрочные \\
\hline 0,25 & 0,50 & 1 \\
\hline
\end{tabular}

Таблица 2. Факторы внутреннего влияния

\begin{tabular}{|l|l|}
\hline $\begin{array}{l}\text { Доля сотрудников с высшим образованием от общего } \\
\text { числа сотрудников }\end{array}$ & Показатель лояльности сотрудников (eNPS) \\
\hline $\begin{array}{l}\text { Доля креативных сотрудников (результаты труда } \\
\text { идолжностные обязанности включают генерацию }\end{array}$ & $\begin{array}{l}\text { Доля сотрудников, регулярно перерабатывающих } \\
\text { норму рабочего времени }\end{array}$ \\
\hline $\begin{array}{l}\text { Число персональных компьютеров по отношению к } \\
\text { общему числу сотрудников }\end{array}$ & $\begin{array}{l}\text { Соответствие желаемой корпоративной культуры и } \\
\text { реально существующей }\end{array}$ \\
\hline Доля сотрудников со стажем более 2 лет & Доля поощряемых инициатив сотрудников \\
\hline $\begin{array}{l}\text { Доля сотрудников, проходящих обучение или курсы } \\
\text { повышения квалификации мин. раз в год }\end{array}$ & $\begin{array}{l}\text { Доля сотрудников, регулярно и полноценно исполь- } \\
\text { зующих отпуск }\end{array}$ \\
\hline $\begin{array}{l}\text { Уровень удовлетворенности сотрудников имеющейся } \\
\text { системой управления в проектах }\end{array}$ & Наличие в компании программ wеll-being \\
\hline $\begin{array}{l}\text { Уровень горизонтальной и вертикальной мобильно- } \\
\text { сти сотрудников }\end{array}$ & $\begin{array}{l}\text { Уровень затрат на программы well-being в организа- } \\
\text { ции }\end{array}$ \\
\hline
\end{tabular}




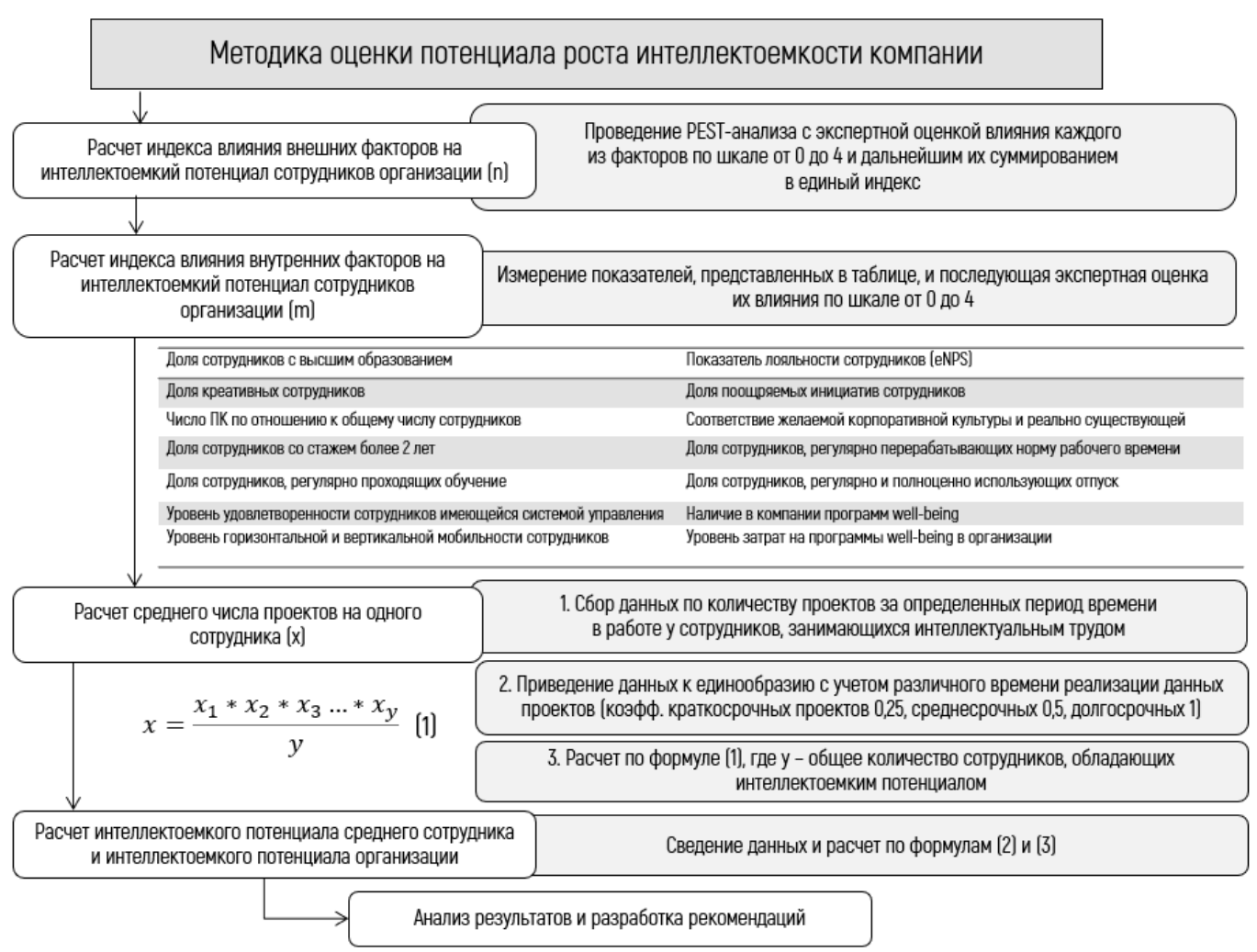

Рисунок 3. Методика оценки потенциала роста интеллектоемкости компании

рующихся под действием технологических инноваций, учитывает особенности как интеллектоемких компаний, так и сотрудников, занятых интеллектуальным и/или творческим трудом и созданием нового, что обеспечивает возможно- сти по принятию стратегических управленческих решений через призму важности человеческого и интеллектуального капиталов и работать над их качеством и развитием для развития организации.

\section{Библиографический список}

1. Величенкова Д. С., Родионов Д. Г. Методика оценки эффективности региональной инновационной системы с учетом влияния университетов //Инновации и инвестиции. - 2020. - № . 8.

2. Клейнер Г.Б. Интеллектуальная теория фирмы // Вопросы экономики, 2021._N 1._ С. $73-97$.

3. Клейнер Г.Б. Интеллектуальная экономика нового века: экономика постзнаний // Экономическое возрождение России, 2020.- № 1.- С. 35-42.

4. Родионов Д. Г., Данияли С. М., Мокеева Т. В. Формирование интегрированной системы управления в контексте развития инновационного менеджмента //Вестник университета. - 2020. - № . 5 .

5. Харламова Т.Л. Инновационная система образования и развитие человеческого капитала //Российский экономический интернет-журнал. - 2019. - № . 1.- С. 74-74.

6. Шульте Б. Мне некогда! В поисках свободного времени в эпоху всеобщего цейтнота // Издательство МИФ.2015.-368 c.

7. Grimshaw D., Miozzo M. Human capital and productivity: a call for new interdisciplinary research// The Productivity Institute, 2021.- 41 p.

8. Okorokov R., Timofeeva A., Kharlamova T. Building intellectual capital of specialists in the context of digital transformation of the Russian economy //IOP Conference Series: Materials Science and Engineering.- IOP Publishing, 2019.- T. 497.- № . 1.-C. 012015.

9. Vrdoljak-Raguž, I., Jelenc, L., \& Podrug, N. Neostrategic Management - An International Perspective on Trends and Challenges // Switzerland: Springer International Publishing. - 2016. - 241 p. 